\title{
Análisis de libros de texto en Brasil y en España: una introducción al tema en el área de Educación Física
}

\author{
Rafael Guimarães Botelho* \\ Marcos Garcia Neira**
}

\begin{abstract}
Resumen: El objetivo de este artículo es revisar los trabajos que se centran en el análisis de libros de texto en Educación Física. Los 17 trabajos recuperados, entre 2000 y 2012, revelan que en las imágenes de los libros prevalecen mujeres con cuerpos delgados y hombres musculosos. Sin tener en cuenta la diversidad étnica, etaria y multiforme, las imágenes preconizan personas blancas y atléticas. Por ende, se puede afirmar que aún prevalecen estereotipos, prejuicios y discriminaciones con relación al género, edad, etnia, raza y patrones corporales en las imágenes y textos de los libros analizados por los autores brasileños y españoles.
\end{abstract}

Palabras clave: Libros de texto. Educación Física. Brasil. España

\section{INTRODUCCIÓN ${ }^{1}$}

En Brasil cuando se hace alguna referencia al libro de texto en Educación Física el enfoque académico de los autores se centra únicamente en la elaboración y utilización de este tipo de material curricular, tal como se puede verificar consultando los trabajos publicados en este país (DINIZ; DARIDO, 2012; RODRIGUES; DARIDO, 2011; DARIDO et al., 2010; GALATTI; PAES; DARIDO, 2010).

\footnotetext{
*Instituto Federal de Educação, Ciência e Tecnologia do Rio de Janeiro. Rio de Janeiro, RJ. Brasil. E-mail: rafaelgbotelho@ig.com.br

**Faculdade de Educação. Universidade de São Paulo. São Paulo, SP. Brasil. E-mail: mgneira@usp.br /

${ }^{1}$ Las citas directas e indirectas tomadas de los textos en portugués han sido traducidas por los autores de este trabajo.
} 
No obstante, el análisis de libros de texto es una etapa que debe preceder la elaboración y la aplicación de dichos materiales en el practicum de la asignatura de Educación Física. Esta idea se confirma con el pensamiento de expertos en el área: "la elaboración de materiales para una etapa educativa determinada podría ser una propuesta posterior al análisis" (DEVÍS DEVÍS; PEIRÓ VELERT, 2004, p. 88); “[...] el docente no debe recurrir a los libros sin un análisis crítico y reflexivo previo. La sensatez en base a criterios educativos previamente establecidos es imprescindible en el uso de este recurso didáctico" (TÁBOA PAIS; REY CAO, 2007, p. 27).

En el ámbito anglófono, el tema del análisis de libros de texto ya había sido abordado en la tesis doctoral Sexism in elementary Physical Education literature: a content analysis (HILDRETH, 1979).

Sin embargo, aún son muy poco conocidos y discutidos los textos publicados que se centran en el análisis o en la evaluación de variables relacionadas con la Educación Física y el Deporte en los libros de texto en general, y en los libros de texto de Educación Física en particular. En otras palabras, en Brasil todavía no existe una revisión de tales trabajos.

Así, y en base a todo lo expuesto, se plantean los siguientes interrogantes:

¿Es posible analizar y evaluar variables relacionadas con la Educación Física y el Deporte en los libros de texto?

¿Qué variables analizan los autores que investigan los libros de texto de Educación Física?

Con el fin de dar respuesta a la pregunta planteada, el objetivo general de este artículo es revisar los trabajos que se centran en el análisis y en la evaluación de libros de texto en el área de Educación Física en Brasil y en España.

Para ayudar a la consecución de este objetivo, se establecen los siguientes objetivos específicos:

Movimento, Porto Alegre, v. 20, n. 2, p. 659-685, abr.jun. de 2014. 
a) crear un cuadro descriptivo que posibilite la presentación de los datos derivados de los trabajos recuperados;

b) cuantificar el objeto de estudio y las variables de análisis que esos autores identificados eligieron para analizar y evaluar los libros de texto.

\section{Materiales y métodos}

\subsection{EL ANÁLISIS DOCUMENTAL}

Para Chaumier (1993, p. 17), el análisis documental es "[...] una operación o un conjunto de operaciones encaminadas a representar el contenido de un documento bajo una forma diferente de su forma original, con la finalidad de facilitar su consulta o su localización en una fase posterior".

En términos sencillos, “[...] el análisis documental permite pasar de un documento primario (bruto) a un documento secundario (representación del primero). Esto es lo que son, por ejemplo, los resúmenes o extractos (condensación del documento según ciertas reglas)" (BARDIN, 2002, p. 35).

Por consiguiente, el análisis documental empleado permitirá presentar las unidades de significación (descritas en el cuadro de resultados) que los trabajos identificados y recuperados han elegido para el análisis de los libros de texto. Por tanto, este tipo de análisis permite el control documental y la recuperación de información (LÓPEZ YEPES, 2004).

\subsection{PRocedimientos UtILIZADOS EN LA REVISIÓN DE LA LITERATURA}

Heinemann (2008, p. 41) recuerda que "[...] es imposible abarcar todo; por tanto, hay que establecer criterios que delimiten la búsqueda y la lectura de la literatura [...]."

Movimento, Porto Alegre, v. 20, n. 2, p. 659-685, abr.jun. de 2014. 
Por ende, para llevar a cabo esta revisión se siguió el esquema de la Figura 1.

Figura 1: Plan del procedimiento: revisión de la literatura

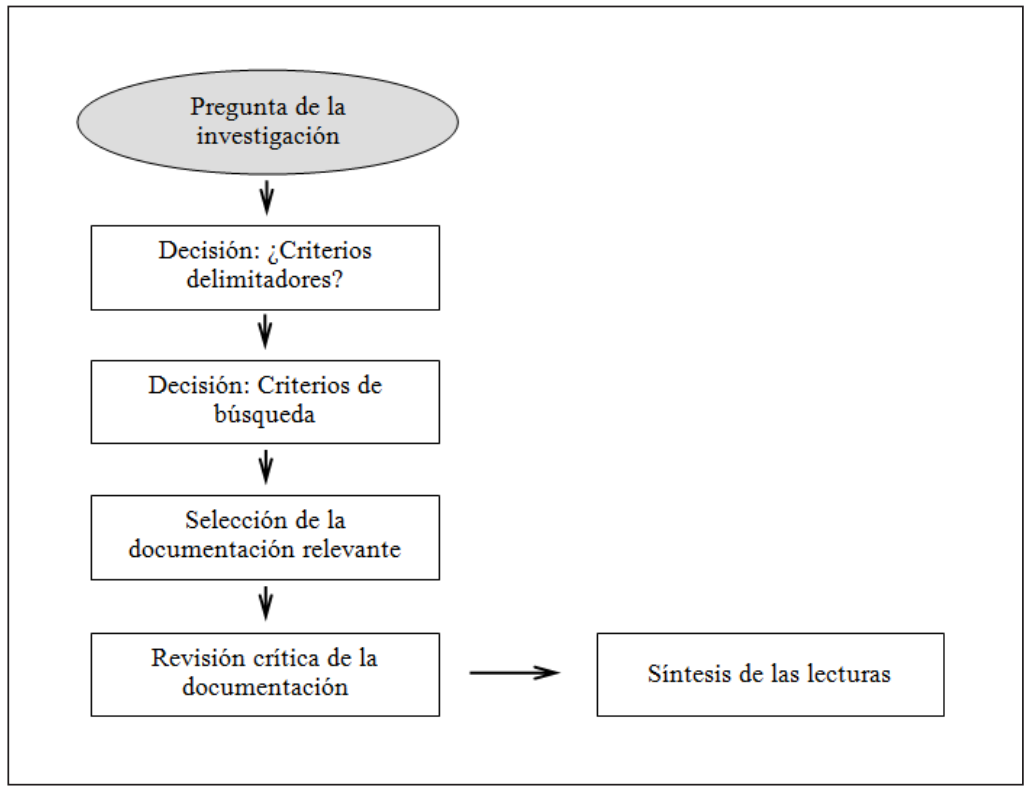

Fuente: HEINEMANN, 2008, p. 39.

\subsubsection{FUENTES DE INFORMACIÓN PARA LA BÚSQUEDA}

En esta revisión se han utilizado tres categorías de fuentes de información, según los criterios adoptados por Grogan (1982), Cunha (2001) y Pereira (2012): fuentes primarias, secundarias y terciarias.

- Fuentes primarias. Revistas científicas en dos ámbitos lingüísticos.

Lengua castellana: Revista Kronos; Revista Española de Educación Física y Deportes; Revista Internacional de

Movimento, Porto Alegre, v. 20, n. 2, p. 659-685, abr./jun. de 2014. 
Medicina y Ciencias de la Actividad Física y del Deporte; Tándem: didáctica de la Educación Física; Lecturas: EF y Deportes; Educación Física y Deporte.

Lengua portuguesa. Revista Movimento; Revista Brasileira de Ciências do Esporte; Revista Brasileira de Educação Física e Esporte; Revista Motriz; y Revista Pensar a Prática.

- Fuentes secundarias. Catálogos, buscadores, respositorios y bases de datos en dos ámbitos lingüísticos.

Lengua castellana. La base Dialnet, la base de tesis doctorales (TESEO) del Ministerio de Educación, Cultura y Deporte de España, el repositorio TDX (Tesis Doctorals en Xarxa) y la RED de Bibliotecas Universitarias Españolas: catálogo colectivo de REBIUN.

Lengua portuguesa. El Portal Domínio Púbico, el Banco de Teses da Coordenação de Aperfeiçoamento de Pessoal de Nível Superior (CAPES) y el Núcleo Brasileiro de Dissertações e Teses em Educação, Educação Física e Educação Especial (NUTESES).

Además, se ha utilizado el buscador Google en los dos idiomas.

- Fuentes terciarias. Bibliotecas do Centro de Educação e Humanidades da Universidade do Estado do Rio de Janeiro (UERJ) y de la Faculdade de Educação da Universidade de São Paulo (USP).

2.2.2 CRITERIOS DE BÚSquedA

- Período de búsqueda: las búsquedas se realizaron entre los meses de junio y diciembre de 2012.

- Palabras clave utilizadas en la búsqueda: se utilizaron las palabras clave "Libros de texto", "Educación Física" y "Deporte". En portugués, "Livros didáticos", "Educação Física" y "Esporte".

Movimento, Porto Alegre, v. 20, n. 2, p. 659-685, abr.jun. de 2014. 
2.2.3 Delimitación del objeto de estudio

A continuación, se presentan las delimitaciones establecidas para llevar a cabo la revisión de la literatura.

- Delimitación por tipo de publicación. Se incluyeron en este trabajo tesinas de máster, tesis doctorales, artículos de revistas, actas de congresos, libros y capítulos de libros.

- Delimitación temporal. Se investigaron los trabajos publicados entre los años 2000 y 2012.

- Delimitación linguística. Los trabajos recuperados fueron publicados en castellano y en portugués.

\section{Resultados}

\subsection{ANÁLISIS Y EVALUACIÓN DE VARIABLES RELACIONADAS CON LA EDUCACIÓN FÍSICA Y EL DEPORTE EN LOS LIBROS DE TEXTO DE OTRAS ASIGNATURAS ESCOLARES}

Silveira (2000) analizó en las ilustraciones y textos de los libros de texto de Estudios Sociales, Historia, Geografía y Ciencias (un libro por asignatura) los modelos vigentes de las personas mayores con relación a las actividades físicas.

Los resultados indicaron que un total de 58 ilustraciones y dos citas hacen referencia a las actividades físicas. "De todas las ilustraciones identificadas, 52 presentan niños y adolescentes, mientras que las ocho restantes difunden una imagen de adultos. Consecuentemente, ninguna de las ilustraciones y citas hace referencia a las personas mayores" (SILVEIRA, 2000, p. 137).

En su trabajo, Botelho (2005, p. 201) subraya que "[...] los ejercicios y los textos, así como las ilustraciones, refuerzan el contenido ideológico que se desea transmitir".

[...] Consecuentemente, las imágenes, las fotografías, los textos relacionados con la actividad física y el deporte, la salud, la

Movimento, Porto Alegre, v. 20, n. 2, p. 659-685, abr./jun. de 2014. 
recreación y el ocio siguen siendo transmitidos en esos libros (independiente de la asignatura) y acaban creando estereotipos (muchos de ellos negativos), reforzando formas de prejuicios y discriminaciones negativas con relación a la práctica de la Educación Física (BOTELHO, 2005, p. 203).

A continuación, se presenta una imagen difundida en un libro de texto brasileño.

Figura 2: Actividades recreativas de chicos y chicas

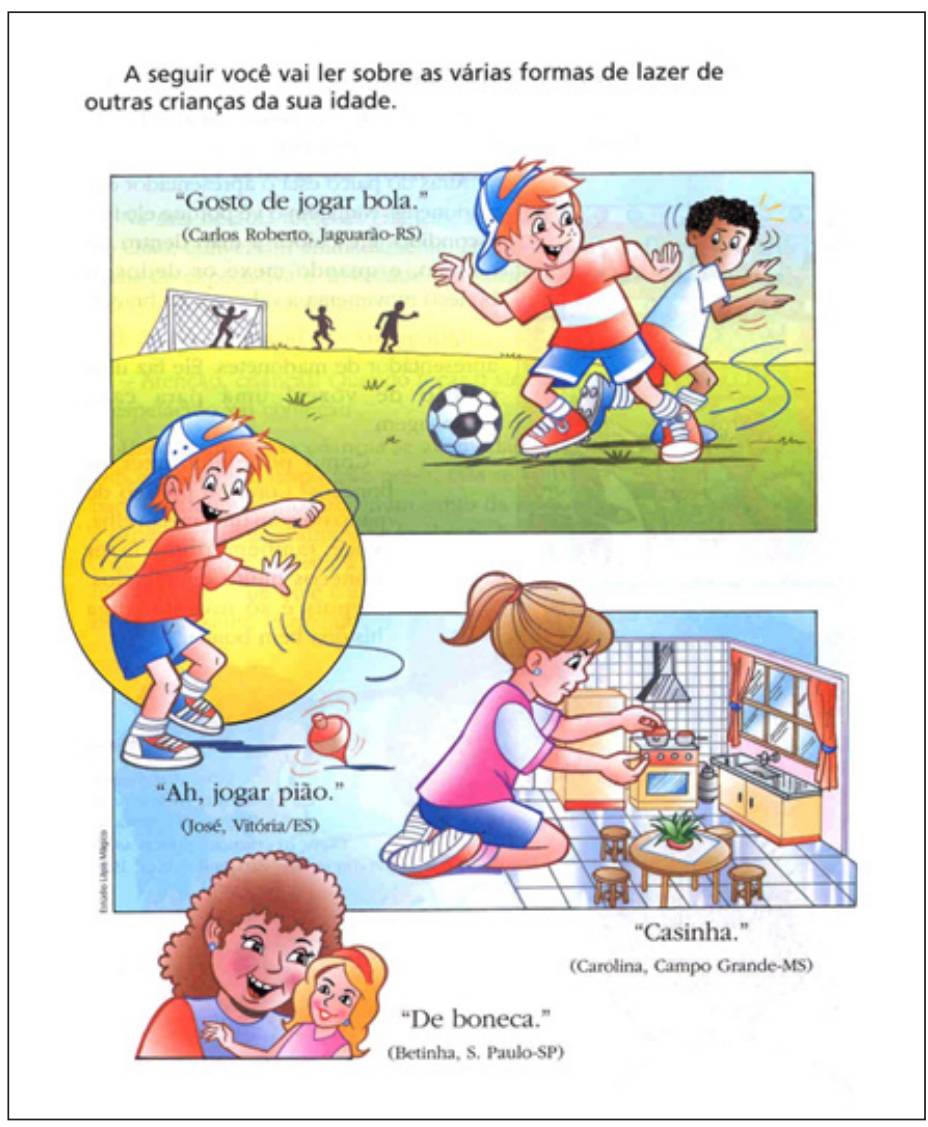

Fuente: MARIN; QUEVEDO; ORDOÑEZ, 2004, p. 184

Movimento, Porto Alegre, v. 20, n. 2, p. 659-685, abr.jun. de 2014. 
La concepción de los autores del libro de texto indica una actividad relacionada con la recreación y el deporte totalmente permeada de estereotipos y discriminaciones sexistas, como la visión androcéntrica de esta imagen (BOTELHO, 2005).

A continuación, se presenta una ilustración - que refuerza aún más el problema del sexismo transmitido a través de imágenes de juegos - tomada de un manual escolar por Michel (1987), en su reconocido trabajo Fuera moldes: hacia una superación del sexismo en los libros infantiles y escolares.

Figura 3: El sexismo en las imágenes de juegos

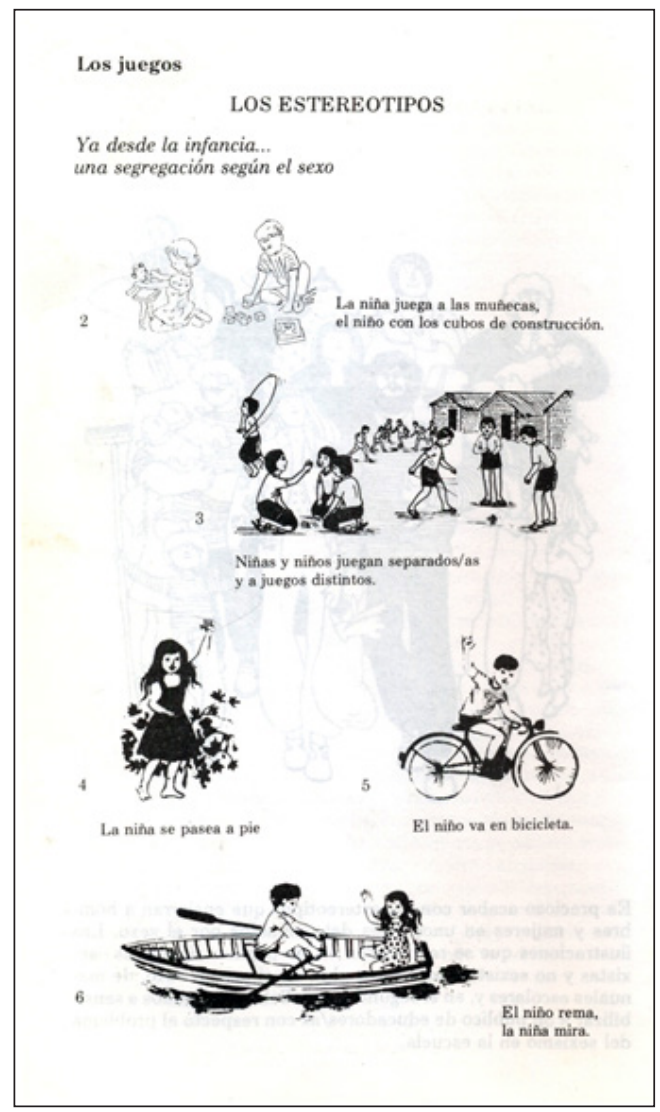

Fuente: MICHEL, 1987, p. 58

Movimento, Porto Alegre, v. 20, n. 2, p. 659-685, abr./jun. de 2014. 
Toscano (2000, p. 62) confirma dicha aserción cuando señala que:

Los libros de texto dirigidos a Primaria y al primer año de Secundaria manifiestan una profunda resistencia a la aceptación de la práctica deportiva femenina en sus contenidos. Siempre que se llega al grupo de las consonantes $t l$ en las cartillas de alfabetización, la palabra frecuentemente utilizada es atleta, y, además, se emplea siempre en masculino, como si la actividad atlética fuera exclusiva de los chicos.

Vicente Nicolás (2009) analizó el tratamiento educativo del movimiento y de la danza en los libros de texto de Educación Musical utilizados en los centros educativos de la Región de Murcia. Para ello, el autor utilizó una muestra de "[...] 728 actividades relacionadas con el movimiento y la danza [...]" (NICOLÁS, 2009, p. 210) en 30 libros de texto de cinco editoriales: Santillana, Alhambra, Anaya, SM y Everest. Algunas conclusiones del estudio son:

- "El tratamiento que tiene el movimiento y la danza en las diferentes editoriales, atendiendo al tipo de actividades y a sus contenidos, debe considerarse variado y con enfoques diferenciados [...]" (NICOLÁS, 2009, p. 445);

- "La escasa propuesta de actividades de movimiento y danza globalizadas con otros bloques de contenidos del área de música" (NICOLÁS, 2009, p. 446);

- "El tratamiento que se hace los contenidos de música desde una perspectiva del movimiento y la danza es superficial [...]" (NICOLÁS, 2009, p. 447).

El artículo publicado por Vicente Nicolás (2010, p. 209) ratifica los resultados encontrados en su tesis, ya que "[...] revelan un tratamiento desigual del movimiento en las diferentes editoriales $\mathrm{y}$ un predominio de las actividades motrices en los libros de los primeros cursos de la etapa".

Movimento, Porto Alegre, v. 20, n. 2, p. 659-685, abr.jun. de 2014. 
3.2 ANÁLISIS Y EVALUACIÓN DE LOS LIBROS DE TEXTO EN EL ÁREA DE EDUCACIÓn Física

La tesis doctoral de Parra Martínez (2002) aborda el sexismo en los libros de texto de Educación Física en $2^{\circ}$ ciclo de ESO y Bachillerato. Su objetivo ha sido conocer si los libros de texto de Educación Física posteriores a la $\mathrm{LOGSE}^{2}$ han eliminado el sexismo y los estereotipos de sus contenidos tal y como la ley lo propone.

Utilizando el análisis de contenido, el autor concluyó que los libros de texto de Educación Física analizados eran sexistas tanto en el lenguaje escrito como en el lenguaje icónico que representaban. Además, se verificó que ninguna de las editoriales investigadas tiene establecidas recomendaciones para la eliminación del sexismo en los libros de texto.

Díaz Crespo (2003) hizo un análisis de contenido de los libros de texto utilizados en los últimos años en Secundaria, en el área de Educación Física. El objetivo del autor fue identificar cómo se distribuían los bloques de contenidos sobre Juegos y deportes, Condición física, Cualidades motrices, Expresión corporal y Actividades físicas en el medio natural.

Díaz Crespo (2003) indicó que existe una desproporción en el tratamiento que se hace de los diferentes bloques temáticos en los manuales analizados. Por ejemplo, los bloques sobre juegos y deportes (con 50\%) y condición física (con 23\%) son los principales y juntos llegan a un $73 \%$ del contenido total.

Estos resultados identificados en los libros de texto analizados permiten comprobar el proceso de deportivización del currículo real de Educación Física en la etapa de Educación Secundaria (DÍAZ CRESPO, 2003).

A su vez, González Pascual (2005, p. 79) investigó “[... s si la Educación Física Escolar alimenta y/o refuerza las ideologías de

2 LOGSE: Ley Orgánica 1/1990, de 3 de octubre, de Ordenación General del Sistema Educativo, publicada por el Miniterio de Educación, Cultura y Deporte de España.

Movimento, Porto Alegre, v. 20, n. 2, p. 659-685, abr.jun. de 2014. 
diferencias de género a través de sus materiales educativos, y en concreto de sus libros de texto [...]"

Para ello, el autor desarrolló un análisis de contenido de 17 libros de texto de ocho editoriales de Educación Física editados para el alumnado de Secundaria Obligatoria (de primero a cuarto de la ESO) y consideró variables como las imágenes, las expresiones linguísticas, los términos y los vocablos utilizados, la cantidad de los personajes masculinos y femeninos representados de forma individual o mixta.

De las conclusiones del estudio de González, se destacan las siguientes:

"[...] Se ha corroborado la existencia de sexismo en la educación física y concretamente en este caso, en los libros de texto" (GONZÁLEZ PASCUAL, 2005, p. 86).

"[...] Se ha comprobado, a tenor de los resultados de este estudio, que los libros de texto son mediadores de transmisión de sexismo en potencia. Por tanto, este material educativo, puede contribuir a mantener unas ideas heredadas en el ámbito de la EFE" (GONZÁLEZ PASCUAL, 2005, p. 87).

Rosário (2006) elaboró una tesina de máster cuyo objetivo fue analizar los contenidos de los libros de texto de Ciencias e Historia, además de relacionarlos con los contenidos de la Educación Física Escolar. La idea era encontrar en estos libros textos e ilustraciones sobre la cultura corporal que puedan ser utilizados por los profesores de Educación Física en sus clases.

Los resultados encontrados indican que los libros analizados presentan una serie de textos e ilustraciones que se relacionan directamente con los contenidos de la Educación Física (ROSÁRIO, 2006).

Marangon (2009) llevó a cabo una tesis doctoral sobre el libro de texto de Educación Física del Estado de Paraná. Esta investigación tuvo por objetivo comprender cómo se constituye el saber en el discurso pedagógico de un libro de texto en Educación Física.

Movimento, Porto Alegre, v. 20, n. 2, p. 659-685, abr.jun. de 2014. 
El análisis realizado identificó que los contenidos estructurantes son el deporte, el juego, la gimnasia, la danza y la lucha (MARANGON, 2009, p. 88). El autor aún añade que: “[...] para ser un alumno competente en Educación Física el libro propone que éste sea capaz de leer, crear hipótesis, investigar, en fin, todas aquellas competencias exigidas para la resolución de problemas".

Una de las conclusiones del estudio señala que:

[...] la movilización del saber en el discurso pedagógico del libro se caracteriza por el énfasis del discurso instructivo dirigido a la reflexión de los aspectos históricos y culturales más amplios de las prácticas corporales [...] (MARANGON, 2009, p. 195).

Rey Cao y Táboas Pais (2006) desarrollaron un instrumento para el análisis de imágenes impresas en los libros de texto de Educación Física en la Educación Secundaria Obligatoria.

Este primer instrumento ha sido perfeccionado, generando una versión final que:

[...] está constituida por dos grandes bloques. El primero de ellos se encarga de recoger las características técnicas de las fotografías: tipo de plano y tipo de enfoque. El segundo bloque se divide, a su vez, en dos grandes dimensiones: cuerpo y actividad física. (TÁBOAS PAIS; REY CAO, 2011, p. 302-304).

A partir de ese instrumento, y con base en la tesis doctoral de Táboas Pais (2009) -dirigida por Rey Cao--, las dos autoras desarrollaron una serie de artículos en los que cada uno investigó una variable en particular (2007; 2009; 2011a; 2011b; 2012). En colaboración con Alba González Palomares, publicaron otro artículo (2010).

En 2007 las autoras analizaron una muestra de 242 imágenes impresas en los libros de texto de Educación Física en la Educación Secundaria Obligatoria.

Movimento, Porto Alegre, v. 20, n. 2, p. 659-685, abr.jun. de 2014. 
A modo de conclusión, las imágenes de los libros de texto analizados representan mayoritariamente un modelo de cuerpo masculino, joven, de raza blanca, cuya tipología corporal es una 'combinación' de diferentes somatotipos y que viste indumentaria deportiva. Las fotografías publicadas por Paidotribo asocian de forma significativa al hombre con los deportes y con la élite deportiva; y a la mujer con otro tipo de prácticas no deportivas y con niveles de 'no élite'. Además, la presencia de individuos de 'otras' razas diferentes a la blanca es insuficiente en las imágenes de las dos editoriales analizadas. En los libros de la editorial Paidotribo estos individuos se vinculan con el deporte y con la competición y no con otro tipo de actividades físicas ni en otros ámbitos como el educativo (GONZÁLEZ PALOMARES , 2007, p. 27).

En otro trabajo, Táboas Pais y Rey Cao (2009, p. 73) muestran que "[...] las imágenes analizadas reflejan mayoritariamente prácticas deportivas - deportes colectivos, especialmente - y reducen considerablemente el resto de posibilidades de práctica motriz".

En su tesis doctoral, Táboas Pais (2009) señala, en las imágenes de los libros de texto de Educación Física, una presencia dominante de un modelo de cuerpo masculino, joven, de raza blanca, cuya tipología corporal es la combinación de somatoti $\neg$ pos y que viste indumentaria deportiva.

González Palomares, Táboas Pais y Rey Cao (2010) investigaron las imágenes de los libros de texto de Educación Física publicados durante la vigencia de la LOGSE y la LOE3. "La muestra estuvo constituida por 3.316 fotografías publicadas bajo el marco legislativos de la LOGSE y 536 fotografías editadas con la actual ley de educación (LOE) [...]" (p. 32).

Se concluye que, de forma general, no existen mejoras substanciales entre los libros de texto de EF publicados durante la vigencia de la

3 LOE: Ley Orgánica 2/2006, de 3 de mayo, de Educación, publicada por el Miniterio de Educación, Cultura y Deporte de España.

Movimento, Porto Alegre, v. 20, n. 2, p. 659-685, abr.jun. de 2014. 
LOGSE y los libros editados con la nueva ley de educación (LOE) con respecto a la representación de la diversidad racial. Los libros de texto de Educación Física siguen perpetuando modelos estereotipados en función de la raza y ofrecen una visión sesgada de su participación en el deporte [...]. (GONZÁlEZ PALOMARES; TÁBOAS PAIS; REY CAO, 2010, p. 36).

En otro estudio identificado (TÁBOAS PAIS; REY CAO, 2011a, p. 99) el objetivo ha sido "reflexionar sobre los modelos de cuerpo vinculados a la actividad física". La muestra estuvo formada por un total de 3.316 fotografias, publicadas en 36 libros de texto de Educación Física.

Los resultados mostraron que no son frecuentes modelos notoriamente delgados y/o musculados en las fotografías de los libros de texto de educación física, aunque sí existe una tendencia a vincular a las mujeres con cuerpos delgados y a los hombres con cuerpos mesomórficos o musculados. Los libros de texto de educación física de la educación secundaria parecen haber iniciado un proceso de cambio frente a las visiones estereotipadas vigentes en el imaginario social.

Las autoras (2011b) publican el texto Las imágenes en los libros de texto de Educación Física de la ESO: modelos corporales y actividade física, cuyo objetivo general fue analizar 242 imágenes impresas de libros de texto de Educación Física de las Editoriales Anaya y Paidotribo.

El tercer artículo publicado en el mismo año (TÁBOAS PAIS; REY CAO, 2011c) tuvo por objetivo identificar en qué se fijan los alumnos y alumnas cuando observan las imágenes de los libros de texto de Educación Física. Los resultados obtenidos revelan la lectura de estereotipos con respecto a la actividad física y el deporte en las imágenes como, por ejemplo, la cultura del músculo, de la delgadez y de la juventud como modelo corporal ideal.

Movimento, Porto Alegre, v. 20, n. 2, p. 659-685, abr./jun. de 2014. 
En trabajo más reciente, Táboas Pais y Rey Cao (2012, p. 52) analizan 3.316 imágenes publicadas en 36 libros de texto de Educación Física.

En conclusión, los datos mostrados en este estudio señalan la reproducción de un modelo tradicional de EF en el período de vigencia de la LOGSE. Las imágenes editadas en los libros de texto de la ESO se vinculan a los contenidos de condición física y deporte. Los deportes gozan de un trato preferente en contraposición con otro tipo de prácticas como las actividades en el medio natural, las actividades artísticas y de expresión corporal, las prácticas de interiorización, o los ejercicios de higiene postural $[\ldots]$.

A continuación, se presenta un cuadro de descripción con una síntesis de las investigaciones que analizaron los libros de texto de Educación Física, además de las variables relacionadas con dicha área en los libros de otras asignaturas escolares.

Cuadro 1: Síntesis de los trabajos que analizan y evalúan los libros de texto de Educación Física o variables relacionadas con esta área en libros de texto de otras asignaturas.

\begin{tabular}{|c|c|c|c|}
\hline AUTORÍA/AÑO & $\begin{array}{c}\text { TIPO DE } \\
\text { TRABAJO / } \\
\text { IDIOMA }\end{array}$ & $\begin{array}{l}\text { OBJETO DE } \\
\text { ESTUDIO }\end{array}$ & $\begin{array}{c}\text { PRINCIPAL(ES) } \\
\text { VARIABLE(S) DE } \\
\text { ANÁLISIS }\end{array}$ \\
\hline $\begin{array}{c}\text { María Inés Táboas Pais } \\
\text { y } \\
\text { Ana Isabel } \\
\text { Rey Cao } \\
\text { (2012) }\end{array}$ & $\begin{array}{c}\text { Artículo } \\
\text { (Castellano) }\end{array}$ & $\begin{array}{l}\text { Libros de texto de } \\
\text { Educación Física } \\
\text { (Ilustraciones) }\end{array}$ & Actividades físicas \\
\hline $\begin{array}{c}\text { María Inés Táboas Pais } \\
\text { y } \\
\text { Ana Isabel } \\
\text { Rey Cao } \\
\text { (2011c) }\end{array}$ & $\begin{array}{c}\text { Artículo } \\
\text { (Castellano) }\end{array}$ & $\begin{array}{l}\text { Libros de texto de } \\
\text { Educación Física } \\
\text { (Ilustraciones) }\end{array}$ & $\begin{array}{c}\text { Visión del } \\
\text { alumnado respecto } \\
\text { a las imágenes }\end{array}$ \\
\hline $\begin{array}{c}\text { María Inés Táboas Pais } \\
\text { y } \\
\text { Ana Isabel } \\
\text { Rey Cao } \\
\text { (2011b) }\end{array}$ & $\begin{array}{c}\text { Artículo } \\
\text { (Castellano) }\end{array}$ & $\begin{array}{l}\text { Libros de texto de } \\
\text { Educación Física } \\
\text { (Ilustraciones) }\end{array}$ & $\begin{array}{l}\text { Género, edad, } \\
\text { raza, somatotipo, } \\
\text { indumentaria y } \\
\text { actividades físicas }\end{array}$ \\
\hline
\end{tabular}

Movimento, Porto Alegre, v. 20, n. 2, p. 659-685, abr.jun. de 2014. 


\begin{tabular}{|c|c|c|c|}
\hline $\begin{array}{c}\text { María Inés Táboas Pais } \\
\text { y } \\
\text { Ana Isabel } \\
\text { Rey Cao } \\
\text { (2011a) }\end{array}$ & $\begin{array}{c}\text { Artículo } \\
\text { (Castellano) }\end{array}$ & $\begin{array}{l}\text { Libros de texto de } \\
\text { Educación Física } \\
\text { (Ilustraciones) }\end{array}$ & $\begin{array}{l}\text { Género, somatotipo } \\
\text { e indumentaria }\end{array}$ \\
\hline $\begin{array}{l}\text { Alba González Palomares, } \\
\text { María Inés Táboas Pais } \\
\text { y } \\
\text { Ana Isabel } \\
\text { Rey Cao } \\
\text { (2010) }\end{array}$ & $\begin{array}{c}\text { Artículo } \\
\text { (Castellano) }\end{array}$ & $\begin{array}{l}\text { Libros de texto de } \\
\text { Educación Física } \\
\text { (Ilustraciones) }\end{array}$ & Raza \\
\hline $\begin{array}{l}\text { Gregorio Vicente Nicolás } \\
\text { (2010) }\end{array}$ & $\begin{array}{c}\text { Artículo } \\
\text { (Portugués) }\end{array}$ & $\begin{array}{l}\text { Libros de texto de } \\
\text { Educación Musical } \\
\text { (Ilustraciones y } \\
\text { Textos) }\end{array}$ & $\begin{array}{l}\text { Movimiento y } \\
\text { danza }\end{array}$ \\
\hline $\begin{array}{l}\text { Davi Marangon } \\
\text { (2009) }\end{array}$ & $\begin{array}{l}\text { Tesis doctoral } \\
\text { (Portugués) }\end{array}$ & $\begin{array}{l}\text { Libro de texto de } \\
\text { Educación Física } \\
\quad \text { (Textos) }\end{array}$ & $\begin{array}{l}\text { Discurso } \\
\text { pedagógico }\end{array}$ \\
\hline $\begin{array}{c}\text { María Inés Táboas Pais } \\
\text { y } \\
\text { Ana Isabel } \\
\text { Rey Cao } \\
\text { (2009) }\end{array}$ & $\begin{array}{c}\text { Artículo } \\
\text { (Castellano) }\end{array}$ & $\begin{array}{l}\text { Libros de texto de } \\
\text { Educación Física } \\
\text { (Ilustraciones) }\end{array}$ & Actividades físicas \\
\hline $\begin{array}{c}\text { María Inés Táboas Pais } \\
\text { (2009) }\end{array}$ & $\begin{array}{c}\text { Tesis doctoral } \\
\text { (Castellano) }\end{array}$ & $\begin{array}{l}\text { Libros de texto de } \\
\text { Educación Física } \\
\text { (Ilustraciones) }\end{array}$ & $\begin{array}{l}\text { Género, edad, } \\
\text { raza, somatotipo, } \\
\text { indumentaria y } \\
\text { actividades físicas }\end{array}$ \\
\hline $\begin{array}{l}\text { Gregorio Vicente Nicolás } \\
\text { (2009) }\end{array}$ & $\begin{array}{c}\text { Tesis doctoral } \\
\text { (Castellano) }\end{array}$ & $\begin{array}{l}\text { Libros de texto de } \\
\text { Educación Musical } \\
\text { (Ilustraciones y } \\
\text { Textos) }\end{array}$ & $\begin{array}{l}\text { Movimiento y } \\
\text { danza }\end{array}$ \\
\hline $\begin{array}{c}\text { María Inés Táboas Pais } \\
\text { y } \\
\text { Ana Isabel } \\
\text { Rey Cao } \\
\mathbf{( 2 0 0 7 )} \\
\end{array}$ & $\begin{array}{c}\text { Artículo } \\
\text { (Castellano) }\end{array}$ & $\begin{array}{l}\text { Libros de texto de } \\
\text { Educación Física } \\
\text { (Ilustraciones) }\end{array}$ & $\begin{array}{l}\text { Género, edad, } \\
\text { raza, somatotipo, } \\
\text { indumentaria y } \\
\text { actividades físicas }\end{array}$ \\
\hline $\begin{array}{c}\text { Luis Fernando Rocha } \\
\text { Rosário } \\
\text { (2006) }\end{array}$ & $\begin{array}{l}\text { Tesina de } \\
\text { máster } \\
\text { (Portugués) }\end{array}$ & $\begin{array}{l}\text { Libros de texto de } \\
\text { Ciencias e Historia } \\
\text { (Ilustraciones y } \\
\text { Textos) }\end{array}$ & $\begin{array}{c}\text { Bloques de } \\
\text { contenidos } \\
\text { (Cultura corporal } \\
\text { / Educación Física } \\
\text { Escolar) }\end{array}$ \\
\hline $\begin{array}{l}\text { Marta González Pascual } \\
\text { (2005) }\end{array}$ & $\begin{array}{c}\text { Artículo } \\
\text { (Castellano) }\end{array}$ & $\begin{array}{l}\text { Libros de texto de } \\
\text { Educación Física } \\
\text { (Ilustraciones y } \\
\text { Textos) }\end{array}$ & Género \\
\hline
\end{tabular}

Movimento, Porto Alegre, v. 20, n. 2, p. 659-685, abr./jun. de 2014. 
Análisis de libros de texto en Brasil y en ...

\begin{tabular}{|c|c|c|c|}
\hline $\begin{array}{l}\text { Rafael Guimarães Botelho } \\
\text { (2005) }\end{array}$ & $\begin{array}{l}\text { Capítulo de } \\
\quad \text { libro } \\
\text { (Portugués) }\end{array}$ & $\begin{array}{l}\text { Libros de texto de } \\
\text { Alfabetización e } \\
\text { Historia } \\
\text { (Ilustraciones y } \\
\text { Textos) }\end{array}$ & Edad y género \\
\hline $\begin{array}{c}\text { Benjamín } \\
\text { Díaz Crespo } \\
\mathbf{( 2 0 0 3 )}\end{array}$ & $\begin{array}{c}\text { Artículo } \\
\text { (Castellano) }\end{array}$ & $\begin{array}{l}\text { Libros de texto de } \\
\text { Educación Física } \\
\text { (Ilustraciones y } \\
\text { Textos) }\end{array}$ & $\begin{array}{c}\text { Bloques de } \\
\text { contenidos } \\
\text { (juegos y deportes; } \\
\text { condición física; } \\
\text { cualidades motrices } \\
\text { expresión corporal; } \\
\text { y actividades físicas } \\
\text { en el medio natural) }\end{array}$ \\
\hline $\begin{array}{l}\text { Juan Parra Martínez } \\
\text { (2002) }\end{array}$ & $\begin{array}{l}\text { Tesis doctoral } \\
\text { (Castellano) }\end{array}$ & $\begin{array}{l}\text { Libros de texto de } \\
\text { Educación Física } \\
\text { (Ilustraciones y } \\
\text { Textos) }\end{array}$ & Género \\
\hline $\begin{array}{c}\text { Plínio Marcelo Decaro } \\
\text { Silveira } \\
\mathbf{( 2 0 0 0 )}\end{array}$ & $\begin{array}{c}\text { Actas de } \\
\text { congreso } \\
\text { (Portugués) }\end{array}$ & $\begin{array}{c}\text { Libros de texto de } \\
\text { Estudios Sociales, } \\
\text { Historia, Geografía } \\
\text { y Ciencias } \\
\text { (Ilustraciones y } \\
\text { Textos) }\end{array}$ & Edad \\
\hline
\end{tabular}

Fuente: datos de la investigación.

A continuación, el Gráfico 1 presenta el cuantitativo del objeto de estudio elegido por los autores presentados en el Cuadro 1.

Gráfico 1: Valores absolutos del objeto de estudio.

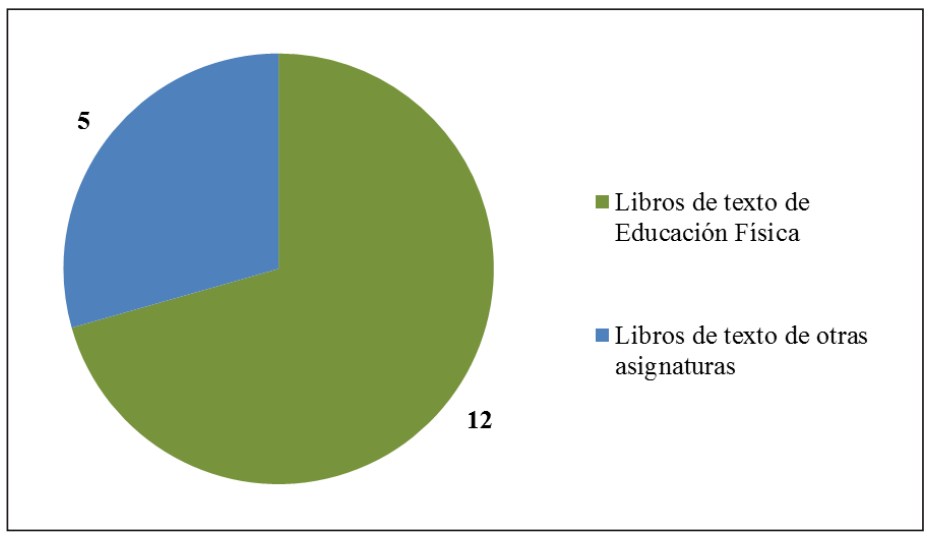

Fuente: datos de la investigación.

Movimento, Porto Alegre, v. 20, n. 2, p. 659-685, abr.jun. de 2014. 
A su vez, el Gráfico 2 describe los valores de las principales variables de análisis elegidas por los autores presentados en el Cuadro 1.

Gráfico 2: Valores absolutos de las principales variables de análisis.

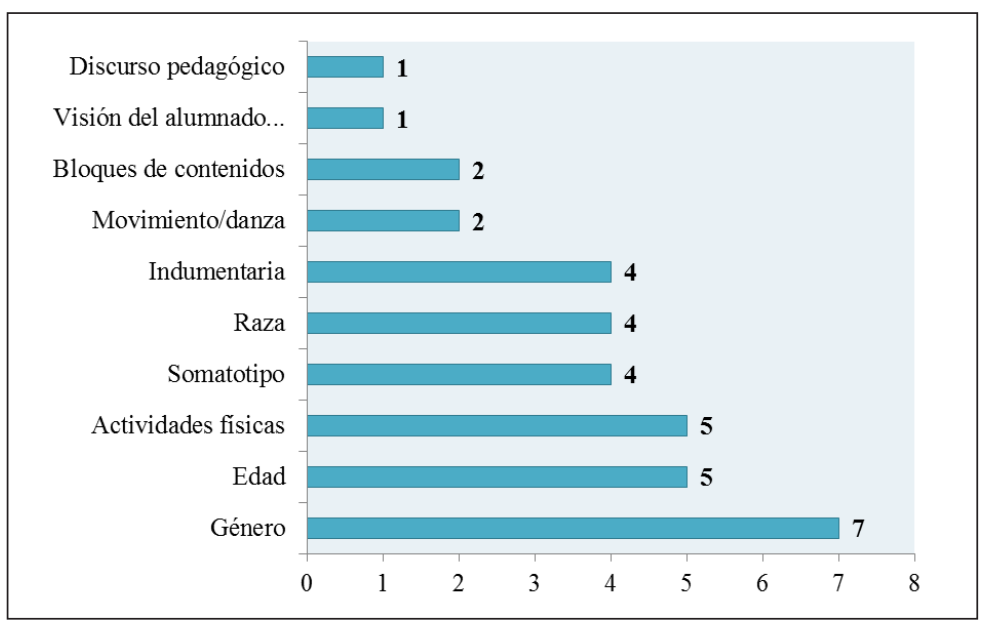

Fuente: datos de la investigación.

\section{Discusıón}

Los pocos trabajos identificados en más de una década se centraron más bien en el análisis, no en la evaluación. En ese sentido, el análisis de contenido ha sido la técnica más utilizada por los autores.

Respecto al objeto de estudio, cinco investigaciones eligieron los libros de texto de otras asignaturas escolares (Alfabetización, Ciencias, Educación Musical, Estudios Sociales, Geografía e Historia), mientras que doce publicaciones analizaron los libros de texto de Educación Física. De estos 17 estudios, ocho analizaron ilustraciones y textos. Además, otros ocho trabajos (todos de Táboas Pais y Rey Cao) se ocuparon únicamente de las ilustraciones y un 
documento (la tesis de Marangon) investigó el texto de un libro de Educación Física.

En términos cualitativos y, principalmente, cuantitativos, ha sido posible comprobar que los trabajos brasileños son todavía escasos si comparados con las publicaciones españolas.

Otra cuestión dice respecto al número considerable de libros de textos de Educación Física publicados en España. Eso, sin lugar a dudas, es una característica que propició a los investigadores del área a elegir esos libros como objeto de estudio en sus investigaciones, aumentando, por consiguiente, la producción académica referente al tema.

Con relación a los trabajos recuperados, el aspecto más interesante recae en las variables de análisis elegidas por los diversos autores. Es justamente en este aspecto que se concentran sus más importantes contribuciones. La amplitud del análisis revela el abanico de posiblidades de este campo de investigación. Por lo general, los autores se centraron en representaciones tendenciosas sobre el cuerpo, las actividades físicas, el género, la raza, la edad y temas de la Educación Física.

Los trabajos analizados revelan que los contenidos de enseñanza relacionados con la Educación Física son difundidos de una manera tradicional, enfatizando un modelo en el que el ejercicio físico se restringe a la competición de alto rendimiento. Aunque hayan ocurrido algunos cambios puntuales, en las imágenes publicadas en los libros de texto prevalecen las mujeres con cuerpos delgados y los hombres musculosos. Sin tener en cuenta la diversidad étnica, etaria y multiforme, las imágenes preconizan personas de raza blanca, atléticas, delgadas y que llevan indumentaria deportiva.

Otros aspectos subrayados por los autores revisados son los que refuerzan los prejuicios como, por ejemplo, la ausencia de personas discapacitadas o con necesidades especiales involucradas en el ámbito deportivo o practicando ejercicio(s) físico(s), y la

Movimento, Porto Alegre, v. 20, n. 2, p. 659-685, abr.jun. de 2014. 
amplia incidencia de la figura masculina en la mayoría de las imágenes, lo que refuerza aún más una postura sexista en el ámbito de las prácticas corporales.

Con base en las constataciones, es posible afirmar que las imágenes y textos escritos -a medida que muestran una noción hegemónica de las prácticas corporales y de sus practicantes- crean estereotipos y refuerzan negativamente las diferencias. Eso, sin duda, genera efectos absolutamente contrarios a una educación democrática, es decir, a una educación que valorice, de manera igualitaria, a todos los grupos que cohabitan la sociedad contemporánea.

\section{Consideraciones finales}

En el campo educativo hay un consenso acerca de las influencias que los libros de texto ejercen en la elaboración de las representaciones del alumnado. Las denuncias de Torres Santomé (2011, p. 86) advierten sobre la manera en la que las personas pertenecientes a los grupos sociales no dominantes son representadas en los materiales didácticos. A título de ejemplo, el autor afirma que:

La mayor parte de los libros de texto en España todavía sostiene el presupuesto filosófico subyacente según el cual, en este mundo, solo existen hombres adultos, de raza blanca, occidentales, de clase media, urbanos y empleados, que además son católicos, heterosexuales, delgados/saludables y robustos.

Según Silva (2008), el modo como los sujetos, sus prácticas, historias y contextos de vida son narrados define la relación que los alumnos establecen con esas identidades culturales. Este hecho justifica la constante atención que el profesorado debe dedicar a los recursos utilizados en el aula, considerándose necesario evitar el riesgo de propagar de imágenes distorsionadas, estereotipadas y despectivas sobre los sectores de la sociedad que disponen de menor poder para difundir sus propias representaciones.

Movimento, Porto Alegre, v. 20, n. 2, p. 659-685, abr./jun. de 2014. 
Aunque el análisis de materiales ofrecidos al alumnado ya se constituya una política en algunos países, el procedimiento es prácticamente incipiente en el área de Educación Física en varios países. Poco se conoce acerca de la forma en la que son representadas las manifestaciones corporales o de sus practicantes en los libros de texto destinados al alumnado. Las investigaciones acerca del asunto, que podrían ayudar a establecer criterios, o a dar a conocer qué tipos de mensajes subliminales difunden, son aún escasas y restrictas a determinados ámbitos linguísticos. Por lo tanto, el presente artículo evidenció la necesidad de dar atención al tema, así como a la socialización de los análisis realizados por los autores brasileños y españoles.

Los pocos trabajos identificados en más de una década se centraron más bien en el análisis, no en la evaluación. En ese sentido, el análisis de contenido ha sido la técnica más utilizada por los autores.

Respecto al objeto de estudio, cinco investigaciones eligieron los libros de texto de otras asignaturas escolares (Alfabetización, Ciencias, Educación Musical, Estudios Sociales, Geografía e Historia), mientras que doce publicaciones analizaron los libros de texto de Educación Física. De estos 17 estudios, ocho analizaron ilustraciones y textos. Además, otros ocho trabajos (todos de Táboas Pais y Rey Cao) se ocuparon únicamente de las ilustraciones y un documento (la tesis de Marangon) investigó el texto de un libro de Educación Física.

Con relación a los trabajos identificados, el aspecto más interesante recae en las variables de análisis elegidas por los diversos autores. Es justamente en este aspecto que se concentran sus más importantes contribuciones. La amplitud del análisis revela el abanico de posiblidades de este campo de investigación. Por lo general, los autores se centraron en representaciones tendenciosas sobre el cuerpo, las actividades físicas, el género, la raza, la edad y temas de la Educación Física.

Los trabajos analizados revelan que los contenidos de enseñanza relacionados con la Educación Física son difundidos

Movimento, Porto Alegre, v. 20, n. 2, p. 659-685, abr.jun. de 2014. 
de una manera tradicional, enfatizando un modelo en el que el ejercicio físico se restringe a la competición de alto rendimiento. Aunque hayan ocurrido algunos cambios puntuales, en las imágenes publicadas en los libros de texto prevalecen las mujeres con cuerpos delgados y los hombres musculosos. Sin tener en cuenta la diversidad étnica, etaria y multiforme, las imágenes preconizan personas de raza blanca, atléticas, delgadas y que llevan indumentaria deportiva.

Otros aspectos subrayados por los autores revisados son los que refuerzan los prejuicios, como por ejemplo, la ausencia de personas discapacitadas o con necesidades especiales involucradas en el ámbito deportivo o practicando ejercicio(s) físico(s), y la amplia incidencia de la figura masculina en la mayoría de las imágenes, lo que refuerza aún más una postura sexista en el ámbito de las prácticas corporales.

Con base en las constataciones, es posible afirmar que las imágenes y textos escritos - a medida que muestran una noción hegemónica de las prácticas corporales y de sus practicantes - crean estereotipos y refuerzan negativamente las diferencias. Eso, sin duda, genera efectos absolutamente contrarios a una educación democrática, es decir, a una educación que valorice, de manera igualitaria, a todos los grupos que cohabitan la sociedad contemporánea.

A principios de 2013 se ha podido identificar 3 artículos recién publicados: Estereotipos sexistas en el ámbito educativo: análisis de las portadas de los libros de Educación Física (HERRADOR SÁNCHEZ, 2013), Estereotipos de sexo y raza en las imágenes de los libros de texto de Educación Física en primaria (MOYA MATA et al., 2013a) y Las imágenes de los libros de Educación Física de primaria desde la perspectiva de género (MOYA MATA et al., 2013b). Eso, sin lugar a dudas, revela en España una tendencia para el aumento de las investigaciones que tienen como objeto de estudio los libros de texto de Educación Física.

Por lo que concierne a las limitaciones de este estudio, la primera tiene que ver con el poco espacio ofrecido a la discusión de

Movimento, Porto Alegre, v. 20, n. 2, p. 659-685, abr.jun. de 2014. 
las tesinas y tesis, ya que es muy complicado (e incluso arriesgado) resumir en pocas líneas estos amplios y minuciosos trabajos. La segunda limitación se refiere a la dificultad en determinar o resumir las variables principales de estudio en algunas de las publicaciones analizadas.

No obstante, y a pesar de las limitaciones presentadas, se puede considerar que este artículo contribuye, en términos prospectivos, con los análisis, y en la elaboración y la utilización del libro de texto en el área de Educación Física.

Analysis of textbooks in Brazil and Spain: an introduction to the subject in Physical Education area

Abstract: This paper has the aim to revise the documents that concentrate on the analysis of textbooks in Physical Education. The 17 documents retrieved, between 2000 and 2012, revealed that in the textbooks' images prevail the women with slim bodies and muscular men. Without taking into account the ethnic, age and multiform diversity, the images exalt white, athletic and slim people. Therefore, it is possible to affirm that stereotypes, prejudices and discrimination in relation to genre, age, ethnic group, race and corporal patterns still prevail in the images and texts of the books analysed by the Brazilian and Spanish authors.

Keywords: Textbooks. Physical Education. Brazil. Spain.

Análise de livros didáticos no Brasil e na Espanha: uma introdução ao tema na área da Educação Física

Resumo: Este artigo tem por objetivo revisar os trabalhos que se centram na análise de livros didáticos de Educação Física. Os 17 trabalhos recuperados, entre 2000 e 2012, revelam que nas imagens dos livros prevalecem mulheres com corpos magros e homens musculosos. Sem levar em conta a diversidade étnica, etária e multiforme, as imagens preconizam pessoas de raça branca, atléticas e magras. Por conseguinte, pode-se afirmar que ainda prevalecem estereótipos, preconceitos e discriminações em relação ao gênero, idade, etnia, raça e padrões corporais nas imagens e textos dos livros analisados pelos autores brasileiros e espanhóis.

Palavras-chave: Livros didáticos. Educação Física. Brasil. Espanha.

Movimento, Porto Alegre, v. 20, n. 2, p. 659-685, abr.jun. de 2014. 


\section{REFERÊNCIAS}

BARDIN, Lawrence. El análisis de contenido. 3. ed. Madrid: Akal, 2002.

BOTELHO, Rafael Guimarães. Contribuições da educação física para a análise das ilustrações sobre esportes contidas em livros didáticos escolares. In: BOTELHO, Rafael Guimarães (Org.). Livro da disciplina "Tendências atuais do ensino de educação física" da Faculdade de Educação da Baixada Fluminense - UERJ. Duque de Caxias: UERJ, Faculdade de Educação da Baixada Fluminense; Niterói: IEG, 2005. p. 201-209.

CHAUMIER, Jacques. Técnicas de documentación y archivo. Barcelona: OikosTau, 1993.

CUNHA, Murilo Bastos da. Para saber mais: fontes de informação em ciência e tecnologia. Brasília: Briquet de Lemos, 2001.

DARIDO, Suraya Cristina. et al. Livro didático na Educação Física escolar: considerações iniciais. Motriz, Rio Claro, v. 16, n. 2, p. 450-457, abr./jun. 2010. Disponível em: <http://www.periodicos.rc.biblioteca.unesp.br/index.php/motriz/ article/view/1980-6574.2010v16n2p450>. Acesso em: 30 ago. 2012.

DEVÍS DEVÍS, José.; PEIRÓ VELERT, Carmen. Los materiales curriculares en la educación física. In: FRAILE, A. (Coord.). Didáctica de la educación física: una perspectiva crítica y transversal. Madrid: Biblioteca Nueva, 2004. p. 63-94.

DÍAZ CRESPO, Benjamin. Los libros de texto como instrumentos de deportivización del currículo real de la Educación Física. Lecturas: EF y Deportes, Buenos Aires, v. 8, n. 56, 2003. Disponível em: <http://www.efdeportes.com/efd56/texto.htm>. Acesso em: 27 enero 2012.

DINIZ, Irlla Karla Santos; DARIDO, Suraya Cristina. Livro didático: uma ferramenta possível de trabalho com a dança na Educação Física Escolar. Motriz, Rio Claro, v. 18, n. 1, p.176-185, jan./mar. 2012. Disponível em: <http://www.periodicos. rc.biblioteca.unesp.br/index.php/motriz/article/view/4972>. Acesso em: 31 ago. 2012.

GALATTI, Larissa Rafaela; PAES, Roberto Rodrigues; DARIDO, Suraya Cristina. Pedagogia do esporte: livro didático aplicado aos Jogos Esportivos Coletivos. Motriz, Rio Claro, v. 16, n. 3, p.751-761, jul./set. 2010. Disponível em: <http:// www. periodicos.rc.biblioteca.unesp.br/index.php/motriz/article/view/19806574.2010v16n3p751>. Acesso em: 30 ago. 2012.

GONZÁLEZ PALOMARES, Alba.; TÁBOAS PAIS, Maria Ines; REY CAO, Ana. Los libros de texto como herramientas para la promoción de una práctica físico-deportiva en igualdad: análisis comparativo de la representación racial entre los libros publicados durante la vigencia de la LOGSE y la LOE. Cuadernos de Psicología del Deporte, Murcia, v. 10, n. 2, p. 31-36, 2010. Suplemento: Monográfico Ciencias de la Actividad Física y Deportes. Disponível em: <http://revistas.um.es/cpd/article/ view/111241>. Acesso em: 30 ago. 2012.

Movimento, Porto Alegre, v. 20, n. 2, p. 659-685, abr./jun. de 2014. 
GONZÁLEZ PASCUAL, Maria. ¿Tienen sexo los contenidos de la educación física escolar? Transmisión de estereotipos de sexo a través de los libros de texto en la etapa de Secundaria. Revista Internacional de Medicina y Ciencias de la Actividad Física y el Deporte, Madrid, v. 5, n. 18, p. 77-88, 2005. Disponível em: <http://cdeporte. rediris.es/revista/revista18/artsexismo8.pdf >. Acesso em: 20 jun. 2012.

GROGAN, Denis. Science and technology: an introduction to the literature. 4th ed. London: C. Bingley, 1982.

HEINEMANN, Klaus. Introducción a la metodología de la investigación empírica en las ciencias del deporte. 2. ed. rev. y ampl. Badalona: Paidotribo, 2008.

HERRADOR SÁNCHEZ, Julio Angel. Estereotipos sexistas en el ámbito educativo: análisis de las portadas de los libros de educación física. Tándem: didáctica de la educación física, Barcelona, n. 41, p. 22-29, ene. 2013.

HILDRETH, Katllen Sexism in elementary physical education literature: a content analysis. 1979. $95 \mathrm{f}$. Thesis (Doctorate of Education) - University of North Carolina at Greensboro, 1979.

LÓPEZ YEPES, Jose. Diccionario enciclopédico de ciencias de la documentación. Madrid: Síntesis, 2004. 2 v.

MARANGON, David. Mobilização para o saber, discurso pedagógico e construção de identidades: uma análise do livro didático público de Educação Física do Estado do Paraná. 2009. 260 f. Tese (Doutorado em Educação) - Setor de Educação, Universidade Federal do Paraná, Curitiba, 2009.

MARIN, Marilu Favarin; QUEVEDO, Julio; ORDOÑEZ, Marlene. História com reflexão: $1^{\text {a }}$. série. São Paulo: IBEP, 2004. (Coleção horizontes).

MICHEL, Andree. Fuera moldes: hacia una superación del sexismo en los libros infantiles y escolares. Barcelona: LaSal, Edicions de les Dones; Unesco, 1987.

MOYA MATA, Irene. et al. Las imágenes de los libros de educación física de primaria desde la perspectiva de género. Tándem: didáctica de la educación física, Barcelona, n. 41, p.41-48, ene. 2013a.

MOYA MATA, Irene. et al. Estereotipos de sexo y raza en las imágenes de los libros de texto de educación física en primaria. Retos: nuevas tendencias en Educación Física, Deporte y Recreación, Murcia, n. 23, p. 14-18, 2013. Disponível em: <http:// www.retos.org/numero_23/14-18.pdf Acesso em: 5 feb. 2013b.

PARRA MARTÍNEZ, Juan. Análisis del sexismo en los libros de texto de Educación Física: $2^{\circ}$ ciclo de ESO y Bachillerato. 2002. 703 p. Tesis (Doctorado en Curriculum y Cultura Organizativa del Centro Fomativo) - Facultad de Educación, Universidad Nacional de Educación a Distancia, 2002.

PEREIRA, Maurício Gomes. Artigos científicos: como redigir, publicar e avaliar. Rio de Janeiro: Guanabara Koogan, 2012.

Movimento, Porto Alegre, v. 20, n. 2, p. 659-685, abr.jun. de 2014. 
REY CAO, Ana; TÁBOAS PAIS, Maria Inés. Instrumento para el análisis de las imágenes en los libros de texto de educación física. In: CONGRESO DE LA ASOCIACIÓN ESPAÑOLA DE CIENCIAS DEL DEPORTE, 4., 2006, A Coruña. Actas... A Coruña: Universidade da Coruña, 2006. p. 530-537.

RODRIGUES, Heitor de Andrade; DARIDO, Suraya Cristina. O livro didático na educação física escolar: a visão dos professores. Motriz, Rio Claro, v. 17, n. 1, p. 48-62, jan./mar. 2011. Disponível em: <http://www.periodicos.rc.biblioteca.unesp. br/index.php/motriz/article/view/3419>. Acesso em: 31 ago. 2012.

ROSÁRIO, Luis Fernando Rocha. A educação física na escola e suas interfaces com os conteúdos de História e Ciências nos livros didáticos. 2006. $184 \mathrm{f}$. Dissertação (Mestrado em Ciências da Motricidade) - Instituto de Biociências, Universidade Estadual Paulista, Rio Claro, 2006.

SILVA, Tomaz Tadeu da. Currículo e identidade social: territórios contestados. In: SILVA, T. T. (Org.). Alienígenas na sala de aula: uma introdução aos estudos culturais em educação. Petrópolis: Vozes, 2008.

SILVEIRA, Plinio Marcelo Decaro. Atividades físicas, pessoas idosas e os modelos vigentes no livro didático. In: SEMINÁRIO INTERNACIONAL SOBRE ATIVIDADES FÍSICAS PARA A TERCEIRA IDADE, 3., 2000, Rio de Janeiro. Anais... Rio de Janeiro: UERJ/UnATI, 2000. p. 135-140.

TÁBOAS PAIS, Maria Inés. Análisis de los estereotipos corporales y de los modelos de actividad física representados en las imágenes de los libros de texto de educación física. 2009. 670 p. Tesis (Doctorado en Investigación en Didácticas Especiales y Educación Física y Deportiva) - Departamento de Didácticas Especiales, Facultad de Ciencias de la Educación y del Deporte, Universidad de Vigo, 2009.

TÁBOAS PAIS, Maria Inés; REY CAO, Ana. Los contenidos de la Educación Física en Secundaria: un análisis de las actividades físicas que se enseñan en las imágenes de los libros de texto. Apunts: Educación Física y Deportes, Barcelona, n. 107, p.45-53, 2012.

TÁBOAS PAIS, Maria Inés; REY CAO, Ana. Los modelos corporales en la actividad física y el deporte: hacia una superación de los estereotipos desde la educación física escolar. Revista Española de Educación Física y Deportes, Madrid, v. 63, n. 392, p. 99-118, 2011a.

TÁBOAS PAIS, Maria Inés; REY CAO, Ana. Las imágenes en los libros de texto de Educación Física de la ESO: modelos corporales y actividade física. Revista de Educación, Madrid, n. 354, p. 293-322, enero-abr. 2011b. Disponivel em: <http://www.educacion.gob.es/dctm/revista-de-educacion/articulos-re354/re35412. pdf?documentld=0901e72b811e1d34>. Acesso en: 30 ago. 2012.

TÁBOAS PAIS, Maria Inés; REY CAO, Ana. Las imágenes de los libros de texto de educación física: percepción y opinión del alumnado. Tándem: didáctica de la Educación Física, n. 36, p. 103-111, abr. 2011c.

Movimento, Porto Alegre, v. 20, n. 2, p. 659-685, abr./jun. de 2014. 
Análisis de libros de texto en Brasil y en ...

TÁBOAS PAIS, Maria Inés; REY CAO, Ana. La deportivización del curriculum de educación física en las imágenes de los libros de texto de la ESO. Kronos: enseñanza de la actividad física y el deporte, Madrid, v. 8, n. 16, p. 71-74, 2009. Disponível em: <http://www.revistakronos.com/docs/File/kronos/16/Kronos_16_10. pdf>. Acesso em: 08 jul. 2012.

TÁBOAS PAIS, Maria Inés; REY CAO, Ana. El cuerpo en las imágenes de los libros de texto de educación física: análisis de dos editoriales. Kronos: la revista científica de actividad física y deporte, Madrid, v. 6, n. 11, p. 22-28, ene./jun., 2007.

TORRES SANTOMÉ, Jurjo. O Cavalo de Troia dos conteúdos curriculares. In: APPLE, Michael W.; AU, Wayne; GANDIN, Luís Armando. Educação crítica: análise internacional. Porto Alegre: Artmed, 2011.

TOSCANO, Moema. Estereótipos sexuais na educação: um manual para o educador. Petrópolis: Vozes, 2000.

VICENTE NICOLÁS, Gregório. Movimiento y danza en educación musical: un análisis de los libros de texto de Educación Primaria. 2009. 479 p. Tesis (Doctorado en Valores y Educación) - Facultad de Educación, Universidad de Murcia, 2009.

VICENTE NICOLÁS, Gregório. Las actividades de movimiento en el aula de música: una aproximación a través de los libros de texto. Educatio Siglo XXI, Murcia, v. 28, n. 1, p. 209-226, 2010. Disponível em: <http://revistas.um.es/educatio/article/ view/109791/104481>. Acesso em: 11 sept. 2012.

El presente artículo fue realizado con el apoyo del CNPq, Conselho Nacional de Desenvolvimento Científico e Tecnológico - Brasil.

Rafael Guimarães Botelho

Instituto Federal de Educação, Ciência e Tecnologia do Rio de Janeiro (IFRJ)

Campus Arraial do Cabo

Rua José Pinto de Macedo, s/n, CEP: 28930-000, Prainha, Arraial do Cabo, RJ, Brasil

Campus Rio de Janeiro

Rua Senador Furtado, 121, CEP 20270-021, Maracanã, Rio de Janeiro, RJ, Brasil

Recebido em: 10.08.2013

Aprobado em: 14.03.2014

Movimento, Porto Alegre, v. 20, n. 2, p. 659-685, abr.jun. de 2014. 